\title{
CERTIFICAÇÃO E HOSPITALIDADE: A CABRUCA E A INDICAÇÃO DE PROCEDÊNCIA DO CACAU SUL DA BAHIA COMO PROMOTORES DA PRODUÇÃO DE CHOCOLATES ESPECIAIS
}

\section{CERTIFICATION AND HOSPITALITY: THE CABRUCA AND THE GEOGRAPHICAL INDICATION OF PROVENANCE OF THE COCOA FROM SOUTH BAHIA AS PROMOTERS IN THE PRODUCTION OF SPECIAL CHOCOLATE}

\section{Marcella Sulis}

marcelas-fuscas@hotmail.com

Doutoranda no Programa de Pós-Graduação em Hospitalidade da Universidade Anhembi Morumbi. Professora do Curso de Gastronomia da Universidade Federal do Rio de Janeiro.

ORCID: https://orcid.org/0000-0002-6505-4849

\section{Maria Henriqueta Sperandio Garcia Gimenes-Minasse}

mariegimenes@gmail.com

Professora do Programa de Pós-Graduação em Hospitalidade da Universidade Anhembi Morumbi. Doutora em História e Mestra em Sociologia pela Universidade Federal do Paraná, Bacharel em Turismo pela Universidade Federal do Paraná.

ORCID: https://orcid.org/0000-0002-4952-808X

\section{(9) (1)(2)}

Esta obra está licenciada sob uma licença Creative Commons Attribution-NonCommercial-ShareAlike 4.0 International License.

\section{RESUMO}

Este estudo objetiva analisar como se desenvolveu a rede colaborativa que permitiu a obtenção da certificação de Indicação Geográfica de Procedência do Cacau Sul da Bahia atrelada à produção de chocolates especiais. Por ser uma região tradicional na produção de cacau e chocolates, procurou-se investigar se as relações desenvolvidas neste contexto são alicerçadas por meio de interações hospitaleiras baseadas no acolhimento, no receber, na troca, na retribuição e na relação interpessoal (GOTMAN, 1997). Por meio da pesquisa exploratória e da observação em cinco instituições da região do Sul da Bahia, desenvolveu-se entrevistas com representantes de instituições e produtores locais de cacau e chocolate. Dentre os resultados, destacam-se: a articulação entre produtores de cacau fino e chocolates especiais vinculados às organizações locais como a Associação Cacau Sul Bahia, que vem se constituindo como elo entre tais produtores; a valorização e percepção de que o cacau cabruca é um patrimônio da região cacaueira baiana; a materialização da tradição desta região cacaueira no trabalho coletivo na certificação IP Sul da Bahia; a atuação da ACSB e do CIC apoiando pequenos pro- 
dutores de cacau e chocolates especiais; o fortalecimento dos vínculos entre os atores sociais envolvidos na rede por meio da hospitalidade, manifestada pelo cuidado com os envolvidos nos processos e com o entorno, na qualidade dos produtos como o chocolate especial tree to bar. Este estudo contribuiu para a discussão de ações colaborativas mediadas pela hospitalidade e de valorização de produtos do território como a indicação de procedência do cacau e chocolate especial Sul Bahia.

Palavras-chave: cacau; certificação; indicação de procedência; hospitalidade; chocolate.

\section{ABSTRACT}

This study aims to analyze how the collaborative network that obtained the certification of Geographical Indication of Provenance of Cacao South Bahia was identified and linked to the production of special chocolates. As it is a traditional region in the production of cocoa and chocolates, it should be investigated whether the relationships developed in this context are based on hospitable interactions based on welcoming, receiving, exchange, retribution and interpersonal relationships (GOTMAN, 1997). Through exploratory research and observation in five institutions in the southern region of Bahia, interviews were performed with representatives of local cocoa and chocolate institutions. Among the results, the following stand out: an articulation between producers of fine cocoa and special chocolates linked to local associations such as Associação Cacau Sul da Bahia, which has been connecting such producers; the appreciation and perception that cocoa from the cabruca production model is a heritage of the cocoa-production region in Bahia; the materialization of the tradition of this cacao region in the collective work in the IP Sul da Bahia certification; the actions of ACSB and CIC, supporting small cocoa and specialty chocolate producers; the strengthening of bonds between the social actors involved in the network through hospitality, manifested by the care for those involved in the processes and with the surroundings, in the quality of products such as the special chocolate tree to bar. This study contributed to the discussion of collaborative actions mediated by hospitality and the appreciation of products from the territory, such as the indication of the origin of cocoa and special chocolate from South Bahia.

Keywords: cocoa; certification; indication of origin; hospitality; chocolate.

\section{INTRODUÇÃO}

O consumo consciente e a sustentabilidade na alimentação são temas atuais que incentivam o surgimento de novos modelos de produção e consumo no Brasil e no mundo (GOODMAN; GOODMAN, 2007; SALTINI et al., 2013). Neste processo destacam-se tanto iniciativas voltadas para a produção quanto ao consumo de alimentos em si. 
Em termos de produção surgem novas configurações do sistema social alimentar que buscam ressignificar o papel e a importância de alguns de seus atores sociais, notadamente o papel dos pequenos produtores. Como exemplo menciona-se a adoção de sistemas colaborativos ou sustentáveis de produção de alimentos que estão se confirmando como estratégias promissoras para o desenvolvimento de economias locais, como aqueles que indicam Recanati et al. (2018), que investem em ações inovadoras e colaborativas de integração e verticalização na produção de alimentos e produtos.

Do ponto de vista do consumo, como atestam Callon et al. (2002), mudanças sociais aumentaram a necessidade de distinguir os produtos, inclusive os alimentares. Neste cenário, onde o consumidor é percebido como protagonista e capaz de influenciar todo o sistema social alimentar, os processos de certificações de qualidade e procedência como mecanismos de verificação e comprovação de segurança alimentar - e até mesmo de comprometimento com práticas mais sustentáveis de produção - ganham destaque. Como resultado, novos modos de produção e consumo são reconhecidos e classificados por meio de uma vasta terminologia que busca identificar as especificidades envolvidas no cultivo e na criação de gêneros vegetais e de origem animal, tais como: produção sustentável, agroecológica, orgânica, de agricultura familiar, de cooperativas sustentáveis, indicações geográficas, dentre outros termos.

Este movimento de criação de selos e certificações parece responder à necessidade contemporânea de qualificar e distinguir produtos em um cenário de ampla oferta industrial padronizada onde o consumidor procura, a partir das informações disponíveis, escolher da melhor forma seus alimentos (POULAIN, 2013). Também parece estar associado à ideia de gastro-anomia proposta por Fischler (2011), que remete à desestruturação das regras tradicionais de alimentação (da gramática e da sintaxe do comer) causada pela individualização do ato de comer. Para o autor, esta desestruturação gera insegurança e desconfiança no comensal, que passa a navegar por diferentes fontes de informação e de mediação com a comida, procurando aquela que lhe pareça ter maior credibilidade. A própria noção de "qualidade alimentar" também se multiplica, podendo envolver aspectos nutricionais, organolépticos e também noções de sustentabilidade ambiental e social, valorizando questões de respeito ao entorno e às tradições dos grupos produtores.

Segundo Ilbery e Maye (2007), dentre as formas de qualificação de um produto destaca-se a certificação controlada, um mecanismo que pode atuar de duas maneiras: quando a certificação está diretamente relacionada ao desenvolvimento territorial, que vincula o produto ao território, protegendo assim a identidade local, os modos de vida e as relações na comunidade; ou quando a certificação visa a combinação de produtos específicos com processos, com o objetivo de assegurar os processos produtivos, evitando a produção em larga escala e a injustiça social. 
Mas, se por um lado os alimentos "de origem" estão associados à confiança e à credibilidade, por outro lado muitos produtores que atuam de forma isolada não sabem como valorizar seu produto ou preservar seu processo de produção, o que pode ser contornado por meio de conexões e parcerias estimuladas por redes colaborativas (GALLO et al., 2018; PETRINI, 2009). Salienta-se, neste contexto, a importância da certificação participativa: a obtenção de reconhecimento de forma conjunta com outros produtores. Este processo pressupõe a criação de uma rede colaborativa, na qual os atores envolvidos têm objetivos em comum que garantem a qualidade em todas as etapas até o produto final. Um exemplo notório de rede colaborativa para certificação e produção de chocolates é a Grenada Chocolate Company, que "possui um modelo de negócios interessante, resultante de uma equipe de empreendedores e de uma cooperativa de trabalhadores que se integraram à frente para processar cacau e fabricar barras de chocolate de alta qualidade (valor agregado)" (GALLO et al., 2018, p. 910).

Países como a Itália e França já realizam de forma sistemática e com o apoio de políticas públicas a identificação, a demarcação e a valorização de alimentos com características percebidas como especiais há muitas décadas, associando-as aos territórios em que são produzidos (PETRINI, 2009). No Brasil as ações de reconhecimento de Indicações Geográficas (com as modalidades de Indicação de Procedência e Denominação de Origem) tiveram início no final da década de 1990 sob os auspícios do INPI - Instituto Nacional de Propriedade Intelectual (INPI, 2019a; 2019b).

Como exemplos brasileiros de produtos que obtiveram tal reconhecimento pode-se mencionar o queijo da Serra da Canastra, o café do Oeste da Bahia, o Mel de Ortigueira no Paraná (INPI, 2015; 2019b). Estes alimentos obtiveram Indicação Geográfica na modalidade Indicação de Procedência, que é um instrumento jurídico eficaz que visa a proteção de um produto de uma região com origem de procedência, padrões específicos de produção, controle de qualidade, isto é, um produto diferenciado de uma região "por produzir um produto singular, especial, que possui um 'saber fazer' local característico e uma qualidade diferenciada" (ACSB, s/d).

No ano de 2018 a Associação Cacau Sul Bahia, integrada por produtores de cacau e chocolate da Mesorregião do Sul Baiano, recebeu a certificação de Indicação Geográfica de Procedência (IP) Sul da Bahia pelo INPI. Este reconhecimento foi fruto do trabalho de uma rede colaborativa formada por diferentes atores sociais preocupados em não apenas qualificar a produção, mas também em criar novas estratégias para o fortalecimento dos produtores, com especial atenção para os de pequeno porte. Tal rede é formada por organizações, instituições de pesquisa e produtores de cacau e chocolate, como o CIC (Centro de Inovação do Cacau), a ACSB (Associação Cacau Sul Bahia), a CEPLAC 
(Comissão Executiva do Plano da Lavoura Cacaueira). Observe-se que a Bahia é o estado brasileiro que mais produz amêndoas de cacau e é historicamente vinculado à cultura cacaueira: ali há a chamada "costa do cacau", região que abrange mais de 80 municípios como Ilhéus, Ibirapitanga, Presidente Tavares Neto e Uruçuca, importantes produtores nacionais (ACSB, s./d.). Contudo, nas últimas décadas, a dura realidade da região em termos ambientais e sociais motivou a busca por modelos mais sustentáveis de produção e comercialização, o que culminou na configuração de uma rede colaborativa de suporte para as diferentes etapas, abrangendo desde o cultivo do cacau até a transformação em chocolate pronto para o consumidor final.

Diante da compreensão de que é preciso buscar formas mais sustentáveis para a produção de alimentos, este artigo objetiva analisar como se desenvolveu a rede colaborativa que permitiu a obtenção da certificação de Indicação Geográfica de Procedência Cacau Sul da Bahia e de que forma ela possibilitou o alongamento da cadeia produtiva até a produção de chocolates especiais. De maneira específica, procura-se perceber se as relações desenvolvidas neste contexto são baseadas em interações hospitaleiras, fundamentadas no acolhimento, na troca, no respeito, na relação interpessoal, na retribuição e na sustentabilidade (GOTMAN, 1997; CAMARGO, 2015; TELFER, 2004).

Este trabalho tem natureza exploratória e qualitativa e foi desenvolvido em duas etapas de coleta de dados: a primeira, de caráter documental e bibliográfico, buscou a familiarização com a região estudada e com a discussão de conceitos fundamentais para a compreensão do fenômeno estudado. A segunda etapa consistiu em uma pesquisa de campo desenvolvida a partir de observações diretas não participantes em instituições/organizações ligadas à rede de produtores de cacau e chocolates no sul da Bahia e da realização de entrevistas em profundidade conduzidas por um roteiro semiestruturado.

$\mathrm{Na}$ segunda etapa foram identificados os principais atores e organizações envolvidas na rede produtiva de cacau fino e chocolates especiais, sendo eles: a CEPLAC (Comissão Executiva do Plano da Lavoura Cacaueira), o CIC (Centro de Inovação do Cacau), a ACSB (Associação Cacau Sul Bahia), a UESC (Universidade Estadual de Santa Cruz) e fazendas produtoras de cacau. A observação permitiu compreender os processos relacionados à certificação e à produção de chocolates especiais, bem como a interação entre os atores neste processo. As entrevistas, por sua vez, possibilitaram compreender a formação da rede e recolher informações associadas à produção do cacau e do chocolate, às memórias e às relações envolvidas no cultivo do cacau e da produção do chocolate, às iniciativas realizadas para a obtenção da Indicação Geográfica de Procedência cacau Sul da Bahia e às interações entre as instituições e os produtores com o território/região. As entrevistas foram realizadas com cinco representantes de instituições envolvidas na 
obtenção da indicação geográfica do cacau: a ACSB, o CIC, a CEPLAC, a UESC e um representante dos produtores de chocolate tree to bar. Tais entrevistas foram gravadas e transcritas e a observação foi documentada por meio de registros fotográficos e filmográficos, além de diário de campo. A análise foi realizada por meio da sistematização e interpretação dos dados obtidos de diversas fontes.

Embora o tema sobre o cacau baiano tenha sido explorado em trabalhos anteriores (ESTIVAL, 2013; FONTES, 2013; MATOS, 2018, dentre outros), esta pesquisa se faz inovadora por abordar a conexão da certificação da IP Sul Bahia com modelos tradicionais de produção de cacau (como o sistema cabruca) e a inovação dos chocolates especiais (como a produção de chocolate tree to bar), uma interação que precisa ser melhor compreendida.

\section{TERRITÓRIOS E PATRIMÔNIOS DO CACAU}

O cultivo comercial do cacau iniciou na região sul baiana em 1746 na localidade hoje conhecida como Ilhéus. Devido à boa adaptação do cacau ao clima e solo local, seu plantio tornou-se, no século XIX, uma das principais atividades econômicas da Bahia, responsável pela riqueza de municípios como Ilhéus e Itabuna (SETENTA; LOBÃO, 2012).

$\mathrm{O}$ cacau não trouxe apenas recursos financeiros, desenvolvimento e prestígio para a região. Ele também se integrou à cultura e ao imaginário local, tornando-se tema de inspiração para a literatura (como as obras de Jorge Amado "Cacau", publicada em 1934, e "Gabriela, cravo e canela”, publicada em 1975) e outras manifestações culturais. Esta riqueza, contudo, era concentrada, já que o modelo de desenvolvimento seguia os mesmos padrões relacionados ao café e à cana-de-açúcar, estabelecendo e fortalecendo uma sociedade agrária, patriarcal, baseada em grandes propriedades de terra e inicialmente escravocrata (FREYRE, 2007; WALKER, 2006). Mesmo depois da abolição da escravatura o regime de trabalho manteve seu caráter explorador, tendo em vista as condições de labuta e remuneração para aqueles que se dedicavam à lavoura cacaueira.

Duas crises importantes, ocorridas em 1960 e em 1990, agravaram ainda mais a realidade social vinculada à produção cacaueira. Em 1960 o aumento da produção africana ampliou a oferta das amêndoas no mercado internacional, gerando a queda do preço do cacau. Em 1990, após um período de estiagem que já havia prejudicado as lavouras, muitas plantações foram devastadas pela expansão da praga popularmente conhecida como vassoura-de-bruxa ${ }^{1}$, o que provocou a queda brusca na produção e motivou vários produtores a abandonarem o cacau e buscarem outras alternativas de renda para suas terras (FONTES, 2013).

Este cenário de adversidades incentivou também a realização de novos investimentos para melhoria e recuperação das lavouras, revitali- 
zando a cultura cacaueira. A partir da década de 1990 avanços tecnológicos permitiram a seleção de variedades de planta resistentes ao fungo e o desenvolvimento de técnicas para o controle da doença por órgãos como a CEPLAC (Comissão Executiva do Plano da Lavoura Cacaueira). Por sua vez, as relações hostis de trabalho começaram a mudar, valorizando o agricultor como parte essencial dessa rede.

A cultura cacaueira no sentido amplo também passou a ser valorizada no contexto turístico nas últimas décadas, com fazendas produtoras de cacau e de chocolate desenvolvendo atividades de visitação para aqueles interessados em conhecer os detalhes do cultivo do cacau e o processo produtivo do chocolate de qualidade típico do território Sul Bahia (SANTANA; GOSLING, 2018). Mais recentemente, em 2018, foi lançado pelo governo baiano um roteiro turístico das fazendas de cacau cujo trajeto é feito pela chamada "estrada do chocolate", uma rodovia de $40 \mathrm{~km}$ que abrange 40 fazendas de cacau e chocolate no percurso entre Ilhéus e Uruçuca (FOLHA DE SÃO PAULO, 2018). Neste contexto o chocolate não é percebido apenas como alimento, mas é reconhecido como um símbolo cultural mais amplo que remete à história local e às atividades desenvolvidas pelos diferentes atores da cadeia produtiva de chocolate fino ali produzido.

Outra estratégia fundamental neste processo de revitalização foi o investimento em tecnologia de produção que culminou na agregação de valor aos produtos do cacau, pautada em cultivos sustentáveis e na fabricação de produtos de alta qualidade a partir da verticalização da produção do chocolate fino (ESTIVAL, 2013; FONTES, 2013) a partir da iniciativa da ACSB de dar continuidade à cadeia produtiva do cacau, estendendo as ações desde o cultivo do cacau até a produção do chocolate (FONTES, 2013; MENDES, 2016). Atualmente, embora a produtividade do cacau não tenha sido completamente retomada, de acordo com a Associação Cacau Sul Bahia excelentes níveis de produção estão sendo reconquistados, mantendo o Estado da Bahia como segundo maior produtor nacional, logo atrás do líder Pará.

Observa-se que estas estratégias voltadas para a revitalização da cultura cacaueira na região só se tornaram possíveis a partir da criação de uma rede colaborativa formada por diferentes atores sociais (agricultores e instituições) envolvidos nesse processo. Um exemplo dessas instituições é a CEPLAC: Comissão Executiva do Plano da Lavoura Cacaueira, pioneira em pesquisa e tecnologia sobre cacau. Criada em 1957 esta Comissão hoje faz parte do Ministério da Agricultura e está presente em seis estados brasileiros, Bahia, Espírito Santo, Pará, Amazonas, Rondônia e Mato Grosso. Com o propósito de auxiliar a economia cacaueira, a CEPLAC trabalha desenvolvendo tecnologias, auxiliando nas necessidades das regiões produtoras de cacau do Brasil, buscando estratégias e soluções que possibilitem o crescimento da economia relacionada ao cacau e ao chocolate. Dentre os setores da instituição existe 
o Centro de Pesquisas do Cacau (CPC), que tem como objetivo investir em tecnologias nas áreas de genética, de sustentabilidade, de conservação produtiva e, principalmente, desenvolver clones resistentes à vassoura-de-bruxa. A CEPLAC (2019) possui ainda uma fábrica de chocolate estruturada para trabalhar em toda cadeia produtiva do cacau, do fruto ao pós-colheita até à produção de chocolate.

Como reconhecimento da importância da atuação do CEPLAC na região, a Prefeitura de Itabuna sancionou em 2017 a Lei no. 2.417 reconhecendo a CEPLAC como uma instituição que desenvolve políticas de fomento, como a captação de recursos para região e o desenvolvimento de técnicas mais sustentáveis para a produção cacaueira, como a técnica de plantio do cacau cabruca (MERCADO DO CACAU, 2018), um sistema agroflorestal de cultivo que será abordado posteriormente. Em 2018 a Prefeitura de Ilhéus, por sua vez, sancionou a Lei no 3.904 declarando a CEPLAC como Patrimônio Imaterial e Científico do Município de Ilhéus (MERCADO DO CACAU, 2020).

Para explorar as relações existentes neste contexto, assim como o senso de pertencimento dos envolvidos na certificação e na produção de cacau e do chocolate, é importante refletir sobre a questão do desenvolvimento dos sistemas produtivos locais sob a perspectiva da hospitalidade.

\section{HOSPITALIDADE COMO RELAÇÃO}

Os princípios da hospitalidade funcionam como reguladores das relações sociais, principalmente na interação com um desconhecido, como forma de evitar a agressividade e os comportamentos indesejáveis do outro (CAMARGO, 2015; GOTMAN, 1997). Como uma expressão cultural, a hospitalidade envolve o convite, o acolhimento, a troca e, eventualmente, a hospedagem, a alimentação e o entretenimento, numa relação entre anfitrião e hóspede. É nesse sentido que oferecer algo a alguém expressa a abertura automática para uma relação, mesmo que breve, entre aquele que acolhe e aquele que é acolhido (GODBOUT, 1997; 1999).

Tendo como premissa o fato que a hospitalidade é uma dádiva, entende-se que é uma relação em que se doa (anfitrião), se recebe e se entrega, onde "receber é dar" (MAUSS, 2003). Obrigatório sob o aspecto moral, ritualizado e assimétrico, o fenômeno social da dádiva revela que "as trocas e os contratos se fazem sob forma de presentes, em teoria voluntários, na realidade obrigatoriamente dados e retribuídos" (MAUSS, 2003, p. 187). Assim, uma série de regras e leis não escritas organizam uma sequência de ritos na hospitalidade, como as relações entre anfitrião e hóspede, estranho e convidado, abarcando uma série de rituais como receber, hospedar, entreter, alimentar, baseados em princípios como a relação interpessoal, a virtude, o rito e a troca (CAMARGO, 2015).

A hospitalidade enquanto fenômeno social é fundamental na constituição de redes e laços entre seres humanos, por meio da recepção, da 
comensalidade, dos ritos e do acolhimento. Segundo Gotman (1997), caracterizada por vínculos interpessoais, a hospitalidade se destaca em contraste ao ambiente social cada vez mais individual e hostil das relações humanas.

A hospitalidade é, portanto, uma forma de construção social da relação com o outro marcada pelo acolhimento nas mais diversas sociedades (MONTANDON, 2011). Além disso, é expressa como uma natureza ontológica destacada pela solidariedade moral coletiva, presente nas instituições primárias como a familiar, além de ser uma condição necessária para constituir laços, comunidades e grupos (GODBOUT, 1999; TELFER, 2004). Estaria, portanto, diretamente ligada à sociabilidade, que pode ser exercitada em um contexto primário (entre a família, amigos) ou em um contexto secundário (nas relações estabelecidas com o "mundo externo"), constituindo as relações de pessoa a pessoa e estabelecendo a dádiva como uma trama de relacionamentos sociais interpessoais (GODBOUT, 1999).

As relações sociais também estão associadas com o mundo externo e ao lugar em que se estabelecem. Neste sentido, associado ao respeito e à identificação com o mundo em que habitamos, destaca-se o sentimento de pertencimento e a relação com o território. Zaoual (2006) enfatiza que os humanos possuem um sítio simbólico de pertencimento, que é uma estrutura imaginária de organização social e econômica. Estes territórios simbólicos são como marcadores invisíveis da realidade, considerando o ser humano situado no seu território com sua bagagem teórica e empírica, suas crenças, valores e tradições que, juntos, conduzem a um sentido de comprometimento com as propostas e soluções, respeitando e valorizando as economias locais (SOUSA et al., 2019; ZAOUAL, 2006).

No contexto deste estudo, outro marcador importante é o território em que se encontra o escopo da pesquisa, de modo que a seguir serão descritos aspectos importantes sobre o sistema cabruca de produção de cacau e chocolate, bem como os atores sociais envolvidos nesta conjuntura.

\section{A CABRUCA, A INDICAÇÃO GEOGRÁFICA DE PROCEDÊNCIA DO CACAU SUL DA BAHIA E OS CHOCOLATES ESPECIAIS}

Cabruca é um sistema de plantio do cacau típico do território do sul da Bahia. Baseado na filosofia de cultivo tradicional da região este sistema consiste em "cabrocar" a terra, ou seja, popularmente falando, fazer buracos em meio à floresta para cultivar o cacau sem a retirada de outras espécies nativas. Este sistema de cultivo agroflorestal preserva todo ecossistema existente no território, na medida em que o cacau é cultivado à sombra das árvores nativas da Mata Atlântica e assim, “[...] além de promover a conservação do ambiente natural, esse sistema as- 
segura maior proteção ao ataque de pragas e garante mais qualidade ao fruto" (APPONI et al., 2019, p. 2).

Em 2018 foi apresentado ao Governo do Estado a Indicação No 46/2018 para o reconhecimento do "Cacau Cabruca como Patrimônio Cultural e Imaterial da Bahia e do Brasil”. Na oportunidade argumentou-se que o reconhecimento do sistema cacau-cabruca como Patrimônio Cultural Imaterial seria um passo importante para o reconhecimento do cacau brasileiro, especialmente por tratar-se de um sistema "[...] ecológico de cultivo agroflorestal e, a soma de todos esses valores compõem um ecossistema único, diferenciado e extremamente diversificado, conhecido como ecossistema cacaueiro" (MERCADO DO CACAU, 2020). Tal ação ainda se encontra em processo.

Para além do processo de patrimonialização da cabruca, cabe destacar que para os moradores e produtores de cacau da região o sistema cabruca já é considerado um patrimônio, além disso, há um esforço de entender outros métodos que possam ser trabalhados. Apponi et al. $(2019$, p. 2) ressalta ainda a importância da rede colaborativa no processo de recuperação e disseminação da cabruca: "Essa rede de parceiros é o que fortalece o objetivo de qualificar a cadeia produtiva. Sempre com um olhar mais apurado no campo, pois é lá que começam os desafios".

Verifica-se que o processo de retomada e valorização da técnica cabruca ocorreu porque muitos produtores de cacau, principalmente os pequenos produtores da agricultura familiar, sentiam dificuldade de comprovar a origem do cacau no momento da precificação e venda. Com isto, perceberam que, para efetivar mudanças, precisavam unir esforços. Como estabelecem Gallo et al. (2018, p. 907), "a gravidade de problemas sociais e ambientais implica-se em uma transição necessária que só é possível por meio de ações colaborativas entre atores e organizações, principalmente em locais de certa vulnerabilidade, onde os recursos podem ser escassos". Neste contexto, diversos atores sociais decidiram unir tecnologias e conhecimento em prol da obtenção da certificação de Indicação Geográfica de Procedência do cacau do sul da Bahia, e o sistema cabruca mostrou-se como um diferencial.

Criado em 2010, o projeto para obtenção da Indicação Geográfica de Procedência (IP) reuniu diversos parceiros envolvidos em diferentes etapas da cadeia produtiva do cacau. As ações envolveram atividades relacionadas à valorização do campo, com cursos e treinamentos promovidos pelo CIC (Centro de Inovação do Cacau) e ACSB (Associação Cacau Sul Bahia) sobre o manejo e o plantio do cacau para os agricultores; além de consultoria jurídica para os trâmites legais e de especialistas para a construção de relatórios sobre a história do produto e de diagnósticos relacionados à qualidade e à genética das plantações.

Neste processo, seguindo o que é estipulado pelo INPI, foram criadas normas de uso da Indicação Geográfica, bem como foi criada em 2014 
uma instituição formal, a Associação Cacau Sul Bahia - ACSB, uma entidade formada por cooperativas, associações e instituições sociais que totalizam cerca de 3000 produtores de cacau da região do sul da Bahia. Em janeiro do ano de 2018 foi concedida pelo INPI a Indicação de Procedência Sul da Bahia - IP Sul Bahia, que tem como missão: "Proteger o cacau por meio da Indicação Geográfica Sul Bahia, valorizando os seus aspectos socioeconômicos, culturais e ambientais" (ACSB, s/d).

Observa-se que a elaboração do chocolate de qualidade superior está intrinsecamente relacionada à qualidade da produção do cacau. Desta forma, as preocupações com a qualidade do produto final devem estar presentes desde o início da cadeira produtiva, abrangendo o plantio do cacau, a colheita, a fermentação da semente de cacau (quando ocorre a morte do embrião e a semente se transforma em amêndoa de cacau) e sua secagem (BEG et al., 2017), processos que geram inúmeras modificações sensoriais e preparam a amêndoa para ser triturada e transformada em chocolate.

Verifica-se que a cadeia produtiva do chocolate é extremamente fragmentada na grande indústria, isso porque cada fase é desenvolvida em uma localidade diferente, por processos separados, que muitas vezes não se conectam, o que pode ocasionar uma série de problemas (SALTINI et al., 2013). Neste cenário, a primeira fase da cadeia do chocolate é a produção de cacau que, por ser uma atividade muito específica, se desenvolve somente em países tropicais e úmidos, o que torna a produção restrita a determinadas regiões. Por consequência, os produtores de chocolate fora das zonas de produção dependem da compra de sementes de cacau ou da pasta, que é previamente processada por empresas intermediárias. Cerca de $80 \%$ dos grandes produtores de chocolates do mundo terceirizam o processamento das amêndoas de cacau, comprando a pasta de cacau (liquor ${ }^{2}$ de cacau) e a manteiga de cacau já processadas.

Segundo Recanati et al. (2018) a cadeia de suprimentos para o chocolate é alimentada principalmente por grãos de cacau provenientes de pequenos produtores. Esses grãos são comprados por um atravessador que os revende para cooperativas ou armazéns de cacau. Estas sementes são agrupadas em lotes maiores que são revendidos para uma exportadora/processadora, que geralmente também já processa as amêndoas, revendendo-as para os fabricantes de chocolates. Resumidamente, os maiores beneficiários deste cenário são os agentes intermediários, que compram as sementes a baixo custo e as revendem no mercado.

A produção e venda das sementes do cacau envolvem diversas questões associadas a problemas sociais para os quais as grandes refinadoras de cacau e fábricas de chocolates fecham os olhos ou se abstêm, se aproveitando da vulnerabilidade dessas populações e da situação política e econômica desses países, especialmente quanto aos direitos humanos 
e trabalhistas (GARCÍA-HERRERO et al., 2019). Pode-se mencionar como exemplo, o que ocorre no popularmente conhecido "cinturão do cacau", constituído pelos países africanos Costa do Marfim, Gana, Nigéria e Camarões que, somados, produzem cerca de $70 \%$ de todo cacau consumido no mundo (GARCÍA-HERRERO et al., 2019). Neste cenário, por meio da exploração de pequenos produtores que vendem o cacau a preços extremamente baixos para as grandes empresas intermediárias, as gigantes Barry Callebaut, Olam International e Cargill (atuantes também no Brasil) detêm praticamente o monopólio da cadeia de suprimentos de cacau no mundo (MUSSMAN, 2019). Como resultado, além das consequências ambientais e sociais, ocorre muitas vezes a diminuição da qualidade do produto final por conta da fragmentação na sua rede de suprimentos.

A compra de cacau, quando realizada diretamente pelos produtores de chocolate, encurta a cadeia, evitando outros atores intermediários. Com a compra intermediada, muitas vezes misturam-se as sementes de cacau de inúmeros produtores em lotes maiores, caracterizando lotes heterogêneos de amêndoas de cacau, sem que se saiba a procedência original do cacau, a safra ou o país de origem (RECANATI et al., 2018). Essa diversidade de qualidade nos lotes também ocorre por diferenças no tipo de cultivo e no processamento empregado no cacau, podendo variar de acordo com o país, o produtor, as técnicas de plantio, os padrões de fermentação e de torra, entre outros.

Como alternativa a essa cadeia produtiva insustentável do chocolate, organizações e empresas contrárias às políticas de produção de chocolate vigentes nas grandes indústrias desenvolvem sistemas de produção alternativas. Desta forma, a associação e colaboração de empreendimentos e organizações pode aumentar a chance de sobrevivência na atual economia globalizada, onde grandes empresas globais tendem a controlar o mercado (GARCÍA-HERRERO et al., 2019).

Neste contexto, modelos mais sustentáveis de produção de cacau e chocolates estão ganhando o mercado mundial, como as tendências bean to bar e tree to bar. Apesar do processo existir desde o surgimento do chocolate, o termo bean to bar (da amêndoa à barra) nasceu no final da década de 1990 na Califórnia, Estados Unidos, cunhado por produtores artesanais de chocolate (GILLER, 2017). Esse processo consiste em utilizar a amêndoa de cacau para fazer seu próprio chocolate, ao invés de comprar as barras ou pasta de cacau prontas. Neste caso, a amêndoa não é necessariamente produzida pelo chocolateiro, entretanto, o fabricante de chocolate deve procurar assegurar a qualidade e procedência das amêndoas de cacau (SALTINI et al., 2013). Os produtores de chocolates bean to bar buscam conhecer pessoalmente cada produtor de cacau e verificam pessoalmente a qualidade, o processamento da amêndoa, e o trabalho, pagando um preço mais justo para o produtor. Este segmento cresceu muito nos últimos anos e atualmente é o método mais usual entre os produtores de chocolates especiais. 
Outro tipo de chocolate existente é o tree to bar, "da árvore à barra", resultado de um sistema em que o produtor de cacau também produz o chocolate, inexistindo intermediadores ou setores terceirizados na produção de chocolates. Esse tipo de produção está em ascensão na região cacaueira baiana, com diversas fazendas de cacau investindo na produção do próprio chocolate. Segundo Badaró e Olivetto (2016), a grande vantagem do sistema tree to bar é a combinação com o cacau cabruca, fazendo com que exista um controle de qualidade das etapas de produção do cacau, desde o plantio, a fermentação e a torra da amêndoa de cacau, que são processos essenciais para o chocolate de qualidade superior. No caso do sul da Bahia a união do cacau cabruca com o sistema tree to bar gera um produto de qualidade que respeita a floresta, o território, os animais, os trabalhadores, os produtores e todos os envolvidos nesse processo.

\section{DISCUSSÃO E RESULTADOS}

A região sul baiana, por sua longeva e importante ligação com a história do cultivo e manejo de cacau no Brasil, possui diversos setores de sua sociedade, como organizações públicas e privadas de diferentes naturezas, incluindo instituições de ensino e de pesquisa, envolvidos de alguma forma com a cultura cacaueira e do chocolate.

Dentre estas organizações, destaca-se a já mencionada Associação Cacau Sul Bahia - ACSB, que trabalha para dar maior visibilidade ao cacau e ao chocolate produzidos na região, além de divulgar os benefícios associados à credibilidade proporcionada pela certificação de um produto de qualidade, autorizado por especificações técnicas padronizadas e reconhecidas por órgãos competentes. Fazem parte da ACSB desde pequenos produtores de agricultura familiar até grandes fábricas que produzem em escala análoga à industrial.

De acordo com a entrevista realizada com o diretor da associação, a ACSB trabalha essencialmente três vertentes de ação: a representatividade institucional dos produtores; o acesso ao mercado e marketing dos produtos; e a qualidade do cacau e chocolate. A linha de representatividade é a responsável pelo diálogo dos produtores com as universidades, com o Governo, com o SEBRAE (Serviço Brasileiro de Apoio às Micro e Pequenas Empresas), SENAI (Serviço Nacional de Aprendizagem Industrial), com as instituições de fomento e pesquisa. Por meio dessa linha a Associação trabalha a pesquisa, o desenvolvimento tecnológico e a inovação. Já o acesso ao mercado, promoção e marketing é promovido via instituições parceiras o apoio promocional, como a participação em feiras e a organização de eventos. A terceira vertente de ação, de qualidade, trabalha as ações justamente relacionadas ao selo de qualidade, desenvolvendo pesquisas relacionadas às normas técnicas e às adaptações e mudanças necessárias por parte dos produtores para poderem ter permissão de usar o selo. 
Segundo a gerente de qualidade do CIC a certificação, bem como a ACSB, veio com o intuito de agregar os produtores de cacau da região, combatendo desta forma o individualismo e a rivalidade anteriormente presentes. "Desta forma essas iniciativas fortaleceram o alcance de objetivos maiores. Foi o momento em que era preciso fortalecer e unir os laços dos cacauicultores para que assim a IG pudesse alcançar seu sucesso" (REIS, 2019. Informação verbal).

De acordo com o CIC, essa rede colaborativa que se formou tem como objetivo fortalecer os laços entre os produtores de chocolate e unir forças para o desenvolvimento local, o que era antes impossível diante do domínio do cacau commodity na região. Assim, as instituições e os atores sociais, por meio da troca e do esforço conjunto, se dedicaram a produzir conhecimento comum, como as normas de boas práticas de fabricação e o envolvimento de todos na promoção do selo de qualidade para a rede.

Cabe destacar que, em contextos de redes colaborativas, os laços sociais e afetivos são característicos, assim como as estratégias de manutenção e sobrevivência são desenvolvidas como meio alternativo de constituição. Lugosi (2006) descreve que, para compreensão dos diferentes modos de colaboração e das redes desenvolvidas de modo formal e informal como base de sustentação, deve-se primeiramente compreender o papel central das redes sociais. De modo que os princípios da hospitalidade observados nesta pesquisa foram: o respeito ao entorno, que envolve desde o ser humano até o território habitado, a confiança, o acolhimento, a relação interpessoal, a reciprocidade e, especialmente, as trocas.

Neste contexto, promovendo a certificação do cacau sul Bahia, as organizações CIC e a ACSB se posicionaram como instituições anfitriãs, apoiando e acolhendo pequenos produtores de cacau, cooperativas e grupos da agricultura familiar. Baseadas na relação humana, estas organizações fomentam a valorização do cacau por meio de treinamentos e trocas de conhecimentos entre os atores sociais envolvidos neste processo de certificação.

Como resultado das ações desta rede colaborativa, segundo o presidente da Associação Cacau Sul Bahia (ACSB, 2019), o número de pequenos produtores de cacau que também estão produzindo chocolates vem aumentando significativamente a cada ano, bem como tem aumentado o número de propriedades desenvolvendo atividades turísticas.

Devido aos incentivos, à revalorização e à importância do cacau e do chocolate como patrimônio da região, diversas fazendas de cacau e pequenos produtores ligados às cooperativas de cacau da região decidiram adotar a verticalização da produção do cacau, expandido suas atividades até a elaboração do chocolate. Dentro da própria ACSB existe a associação de produtores de chocolate tree to bar sul da Bahia, que busca uma forma de produção mais sustentável dos pontos de vista ambiental e 
social por meio do respeito ao entorno, às pessoas e ao mundo habitado, bem como pelo zelo e pela preocupação com os processos, com as etapas e, especialmente, com a qualidade do chocolate.

As etapas do ciclo produtivo do chocolate tree to bar também são longas, com a diferença de que não existem agentes e empresas intermediárias, como ilustrado na Figura 1.

\section{Figura 1 - Ciclo produtivo do chocolate tree to bar sul Bahia}

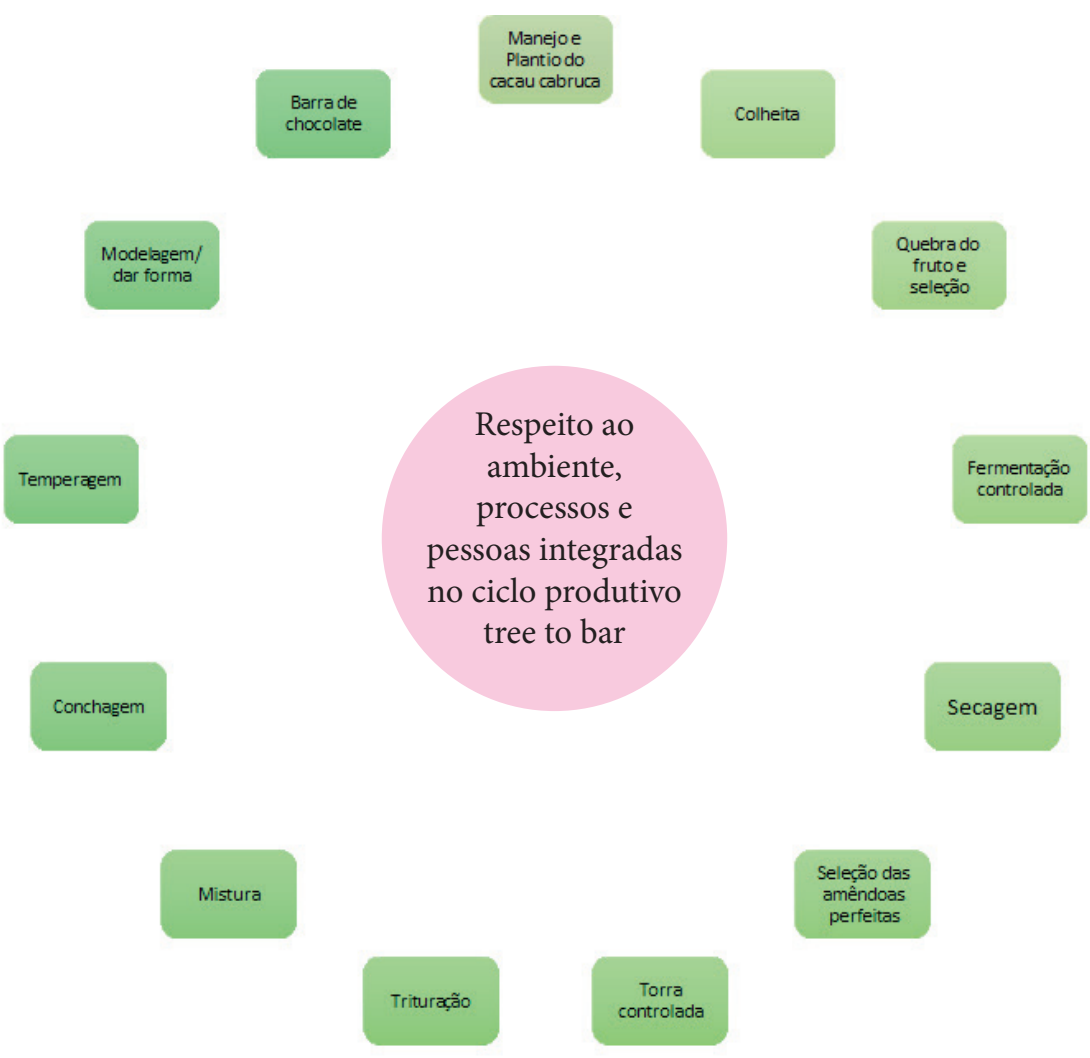

Fonte: as autoras (2020).

Na região do sul da Bahia, de acordo com a ACSB, o chocolate especial tree to bar é produzido com cacau cabruca e amêndoas selecionadas de cacau fino. São cerca de treze etapas para a produção do chocolate tree to bar. As fases incluem desde o manejo adequado do cacau cabruca e cacau fino, fermentação controlada, secagem do cacau com temperatura e tempos corretos. A torra, por exemplo, é uma etapa extremamente importante que, quando feita com temperatura e tempo controlados, evita-se a perda de aromas e sabores característicos de cada safra e variedade de cacau. Em seguida, as amêndoas são descascadas e trituradas, gerando o nibs ${ }^{3}$ de cacau que, em seguida, será moído, transformando-se em liquor. A partir de então, inicia-se o processo de conchagem, que consiste em uma mistura lenta do chocolate, em uma máquina em temperatura de aproximadamente $60^{\circ} \mathrm{C}$ por 8 horas para ganhar esta- 
bilidade, etapa onde serão incorporados açúcar e, dependendo do tipo e da formulação, insere-se o leite. Seguido pela temperagem, processo de resfriamento e aquecimento visando a estabilidade e brilho das gorduras do chocolate, finalizando com a última etapa, da modelagem da barra de chocolate.

De acordo com Marques (2019. Informação verbal), pequeno produtor de cacau e de chocolate tree to bar, todas as etapas são extremamente importantes para a qualidade sensorial final de um chocolate intenso. Segundo ele, chocolate intenso seria o nome correto ao de chocolate amargo. O chocolate amargo seria na verdade o produto de um cacau que foi extremamente torrado em altas temperaturas como forma de se padronizar sabores e mascarar possíveis erros de fermentação do cacau. Para corrigir esse sabor de amargor, que mais seria um sabor de queimado, segundo o especialista, as indústrias adicionam aromatizantes como a baunilha, muito açúcar, leite e lecitina de soja, ingredientes que não precisam ser adicionados nos chocolates bean e tree to bar pela elevada qualidade sensorial natural.

Embora a classificação tree to bar tenha surgido recentemente, tal prática já era desenvolvida por alguns fazendeiros produtores de chocolate na região; entretanto, a primeira classificação adotada pelos produtores de chocolate sul Bahia foi o termo chocolate fino (fine chocolate) ou chocolate intenso. Para ser considerado fino, o chocolate deve reunir uma maior concentração de resíduos sólidos do cacau como o liquor e a manteiga de cacau, bem como deve ser produzido com ingredientes de alta pureza e com fermentação e torra das sementes de cacau controladas adequadamente (CEPLAC, 2019).

De acordo com Reis (2019, Informação verbal), tais classificações, juntamente com a obtenção da Indicação Geográfica de Procedência do cacau sul da Bahia, geraram mais confiança para mais produtores buscarem a certificação e também desenvolverem seus próprios chocolates, agregando valor e qualidade aos seus produtos. Isso fortalece o conceito de qualidade ligado aos pequenos produtores, reforçando a relação com o território e com os valores pautados no desenvolvimento local sustentável (LUGOSI, 2006). Alguns exemplos desses produtores encontram-se descritos no Quadro 1: 
Quadro 1 - Principais produtores de chocolate tree to bar Sul Bahia

\begin{tabular}{|l|l|l|}
\hline Fazenda & Chocolate & Produtor \\
\hline Fazenda Lajedo do Ouro & Var chocolates & Família Magalhães \\
\hline $\begin{array}{l}\text { Fazenda Santa Rita Vale } \\
\text { Potumuju }\end{array}$ & Baiani & Juliana e Tuta Aquino \\
\hline Fazenda Yrerê & Chocolate Yrerê & Gerson Marques \\
\hline Fazenda Sagarana & Chocolate Sagarana & Henrique de Almeida \\
\hline Fazenda Bonança & Mestiço chocolates & $\begin{array}{l}\text { Rogério Kamei e } \\
\text { Cláudia Gamba }\end{array}$ \\
\hline Fazenda Limoeiro & Maltez Chocolate Fino & José Maltez \\
\hline Fazenda Monte Alegre & Amma chocolates & Diego Badaró \\
\hline
\end{tabular}

Fonte: as autoras (2020)

Embora se tenha uma pequena quantidade de produtores de chocolates tree to bar (Quadro 1), de acordo com Marques, diretor da ACSB, existe um movimento forte na região de migração para esse modelo de produção, o que é evidência dos resultados positivos das ações da rede colaborativa e seus desdobramentos.

\section{CONSIDERAÇÕES FINAIS}

A Certificação de Indicação Geográfica de Procedência Cacau Sul da Bahia foi viabilizada por meio do engajamento de produtores de cacau e chocolates, redes, cooperativas e organizações que buscavam o desenvolvimento local, a melhoria do beneficiamento do cacau e a valorização e reconhecimento do chocolate regional. Tais ações foram possíveis pela existência da tradição cacaueira na região e por características específicas daquele território, como a existência da tradicional cabruca.

A busca pela certificação pode ser difícil para os pequenos e médios produtores, tendo em vista eventuais limitações financeiras e de acesso a tecnologias e a informações. Entretanto, o apoio de redes colaborativas pode incentivar e facilitar este processo, melhorando, por consequência, a qualidade de vida de todos os envolvidos na cadeia produtiva do cacau e chocolate. Tais redes se baseiam em objetivos comuns e no forte elo estabelecido entre seus membros. É neste contexto que as interações sociais baseadas na hospitalidade ganham destaque, pois a consolidação e desenvolvimento da certificação foram pautados nas interações respeitosas, a partir da confiança, guiando as transformações na cadeia produtiva do cacau e chocolate. Neste sentido, os princípios da hospitalidade observados nesta pesquisa foram, conforme apontado anteriormente: o respeito ao entorno, que envolve desde o ser humano até o território habitado, a confiança, o acolhimento, a relação interpessoal, a reciprocidade e, especialmente, as trocas. 
Como observado durante a pesquisa, tais princípios atuam de forma integrada e se manifestam de diferentes formas, gerando coesão entre seus elos e favorecendo o desenvolvimento regional. Assim, a hospitalidade se sobressai enquanto relação humana por meio do vínculo social entre os membros associados na rede. Tais vínculos são instituídos e/ou reforçados por meio das trocas, que acontecem, principalmente, pelo intercâmbio de conhecimento específico para a obtenção da Certificação de Indicação Geográfica de Procedência Cacau Sul da Bahia, e para elaboração de chocolates especiais como o tree to bar, além da troca de bens materiais e simbólicos entre os membros da rede.

Por ser um tema novo, o estudo da certificação associada à hospitalidade, considerando também seus atores sociais, possui potencial para pesquisas. Por ser uma iniciativa exploratória, estudos futuros poderiam ampliar a discussão.

\section{NOTAS}

1. A vassoura-de-bruxa é causada pelo fungo Moniliophtora perniciosa, que deixa os ramos do cacaueiro secos como uma vassoura velha e os frutos escuros e sem desenvolvimento (RAMOS, 2006).

2. É a massa pura de chocolate em sua forma bruta, obtida por meio da trituração das amêndoas (nibs) de cacau.

3. Nibs de cacau é a amêndoa de cacau torrada, descascada e quebrada em pequenos pedacinhos; é pela moagem do nibs que se obtém a pasta bruta de chocolate.

\section{REFERÊNCIAS}

ACSB - Associação Cacau Sul da Bahia. s/d. Disponível em: <http:// www.cacausulbahia.org >. Acesso em: 22 set. 2019.

APPONI, Andrea; CARDOSO, Grazielle; GOMES, Ricardo; FERRAZ, Thais; AHMAR, Vinicius. Instituto Arapyaú: modelagem econômica da cabruca. 2019. Disponível em: <https://arapyau.org.br/wp-content/uploads/2019/05/Cabruca_FINAL_reduzida-1.pdf $>$. Acesso em: 11 set. 2020.

BADARÓ, Diego Bertolini; OLIVETTO, Luiza augusta Rabello C. Floresta, cacau e chocolate. São Paulo: Senac São Paulo, 2016.

BARDIN, Laurence. Análise de conteúdo. São Paulo: Edições 70, 2011.

BECKETT, Stephen T. The science of chocolate. Cambridge: The Royal Society of Chemistry Published, 2000.

BEER, Sean; EDWARDS, Jonathan; FERNANDES, Carlos; SAMPAIO, Francisco. Regional Food Cultures: integral to the rural tourism product. In: HALL, M. (org.). Food Tourism around the world. Oxford: Elsevier, 2003. p. 207-221.

BEG, Mohd; AHMAD, Sameer; JAN, Kulsum; BASHIR, Khalid. Status, supply chain and processing of cocoa - a review, v. 66, n. 17, p. 108-116, 2017. 
BRAGA, Isabel Mendes Drumond. O chocolate à mesa: sociabilidade, luxo e exotismo. In: COLÓQUIO FORMAS E ESPAÇOS DE SOCIABILIDADE: CONTRIBUTOS PARA UMA HISTÓRIA DA CULTURA EM PORTUGAL. Anais... Lisboa: Universidade Aberta, 2006.

BROTHERTON, Bob; WOOD, Roy. C. Key Themes in Hospitality Management. In: BROTHERTON, Bob; WOOD, Roy C. (ed.). The Sage Handbook of Hospitality Management. London: Sage, 2007. p. 35-61.

CAILLÉ, Alain. Antropologia do dom: o terceiro paradigma. Petrópolis: Editora Vozes, 2002.

CALLON, Michel; MÉADEAL, Cécile; RABEHARISOA, Vololona. The economy of qualities. Economy and Society, v. 3, n. 2, p. 194-217, 2002.

CAMARGO, Luiz Octávio de Lima. Os interstícios da hospitalidade. Revista Hospitalidade, v. 12, n. 1, p. 42-69, 2015.

CEPLAC - Comissão Executiva do Plano da Lavoura Cacaueira. Cacau fino: conceitos e evolução. 2019. Disponível em: <http://www. ceplac.gov.br/radar/CACAU\%20FINO\%20CONCEITOS\%20E\%20 EVULU\%C3\%87\%C3\%83O\%20NO\%20BRASIL.pdf >. Acesso em: 05 jun. 2019.

CHOCOLATRASONLINE. Chocolates bean to bar é. 2019. Disponível em: <https://chocolatrasonline.com.br/chocolate-bean-to-bar-e/ >. Acesso em: 03 abr. 2020.

CLARENCE-SMITH, Willian. The Global Consumption of Hot Beverages, c.1500 to c.1900. In: NUTZENADEL, A.; TRENTMANN, F. (ed.). Food and globalization: consumption, markets and politis in the modern world. Oxford: Bergpublishers, 2008. p. 37-56.

COE, Sophie; COE, Michael. The true history of chocolate. Nova Iorque: Thames \& Hudson, 2007.

DERRIDA, Jacques. Hostipitality. Angelaki - Journal of the Theoretical Humanities, v. 5, n. 3, p. 3-18, 2000.

ESTIVAL, Katianny. Construção social do mercado de qualidade do cacau no Brasil. Tese (Doutorado em Ciências Sociais) - Programa de Pós-graduação de Ciências sociais em desenvolvimento, agricultura e sociedade, Universidade Federal Rural do Rio de Janeiro, Rio de Janeiro, 2013.

FAO. FAOSTAT. 2017. Disponível em : <www.fao.org/faostat>. Acesso em: 11 dez. 2018.

FISCHLER, Claude. Cultura e gastro-anomia: psicopatologia da alimentação cotidiana. Entrevista concedida a Miriam Goldenberg. Horizontes Antropológicos, Porto Alegre, ano 17, n. 36, p. 235-256, jul./ dez. 2011. Disponível em: <https://www.scielo.br/pdf/ha/v17n36/ v17n36a10.pdf>. Acesso em: 20 nov. 2020.

FREYRE, Gilberto. Açúcar: uma sociologia do doce, com receitas de bolos e doces do Nordeste do Brasil. São Paulo: Editora Global, 2007. 
FOLHA DE SÃO PAULO - Bahia lança roteiro por fazendas de cacau na Estrada do Chocolate, em Ilhéus. 2018. Disponível em: <https:// www1.folha.uol.com.br/turismo/2018/07/bahia-lanca-roteiro-por-fazendas-de-cacau-na-estrada-do-chocolate-em-ilheus.shtml >. Acesso em: 12 set. 2020.

FONTES, Maria Josefina Vervoloet. Do cacau ao chocolate: trajetória, inovações e perspectivas das micro e pequenas agroindústrias de ca$\mathrm{cau} /$ chocolate. Tese (Doutorado em Ciências Sociais) - Programa de Pós-graduação de Ciências Sociais em Desenvolvimento, Agricultura e Sociedade, Universidade Federal Rural do Rio de Janeiro, Rio de Janeiro, 2013.

GALLO, Peter Jack; ANTOLIN-LOPES, Raquel; MONTIEL, Ivan. Associative Sustainable Business Models: Cases in the bean-to-bar chocolate industry. Journal of Cleaner Production, v. 174, p. 905-916, 2018.

GARCÍA-HERRERO, Laura; DE MENNA, Fabio; VITTUARI, Matteo. Sustainability concerns and practices in the chocolate life cycle: Integrating consumers' perceptions and experts' knowledge. Sustainable Production and Consumption, v. 20, p. 117-127, 2019.

GILLER, Megan. Bean to bar chocolate. North Adams: Storey Publishing, 2017.

GODBOUT, Jacques. Récevoir c'est donner. Communications, v. 65, p. 35-48, 1997.

GODBOUT, Jacques; CAILlÉ, Allain. O espírito da dádiva. Rio de Janeiro: Fundação Getúlio Vargas, 1999.

GOODMMAN, David; GOODMAN, Michael. Localism, livelihoods and the 'post-organic': changing perspectives on alternative food networks in the United States. In: MAYE, D.; Kneafsey, M. (ed.). Alternative food Geographies. Elsevier, 2007.

HOLLOWAY, L..; KNEAFSEY, M. (ed.). Alternative food geographies: representation and practice. Amsterdan: Elsevier, 2007. p. 23-28.

GOTMAN, Anne. La question de l'hospitalité aujourd'hui. Communications: L’hospitalité, v. 65, p. 5-19, 1997.

HEINE, Maria Luiza. Jorge Amado e os coronéis do cacau. Ilhéus: Editus, 2007.

ILBERY, Brian; MAYE, Damian. Marketing sustainable food production in Europe: case study evidence from two dutch labelling schemes. Tijdschrift voor Economische em Sociale Geografie, v. 98, n. 4, p. 507-518, 2007.

INPI - INSTITUTO NACIONAL DE PROCEDÊNCIA INDUSTRIAL. Mel de Ortigueira é nova indicação geográfica. 2015. Disponível em: $<$ https://www.gov.br/inpi/pt-br/assuntos/noticias/mel-de-ortigueira-e-nova-indicacao-geografica $>$. Acesso em: 10 nov. de 2020.

INPI - INSTITUTO NACIONAL DE PROCEDÊNCIA INDUSTRIAL. Vai um queijinho ai? 2018a. Disponível em: < https://www.gov.br/turismo/pt-br/assuntos/noticias/vai-um-queijinho-ai>. Acesso em: 03 ago. 2020. 
INPI - INSTITUTO NACIONAL DE PROCEDÊNCIA INDUSTRIAL. INPI concede Indicação Geográfica para queijo e amêndoas de cacau. 2018b. Disponível em: <https://www.gov.br/inpi/pt-br/assuntos/noticias/inpi-concede-indicacao-geografica-para-queijo-e-amendoas-de-cacau >. Acesso em: 03 ago. 2020.

INPI - INSTITUTO NACIONAL DE PROCEDÊNCIA INDUSTRIAL. Selo Arte vai permitir venda de alimentos artesanais entre estados. 2019a. Disponível em: <https://www.gov.br/planalto/pt-br/acompanhe-o-planalto/noticias/2019/07/selo-arte-vai-permitir-venda-da-alimentos-artesanais-entre-estados>. Acesso em: 03 ago. 2020.

INPI - INSTITUTO NACIONAL DE PROCEDÊNCIA INDUSTRIAL. INPI concede registro de indicação geográfica para café do Oeste da Bahia. 2019b. Disponível em: <https://www.gov.br/inpi/pt-br/assuntos/noticias/inpi-concede-registro-de-indicacao-geografica-para-cafe-do-oeste-da-bahia>. Acesso em: 10 nov. 2020.

LOMNITZ, Larissa A. Redes Sociais, organizações, cultura e poder. Rio de Janeiro: E-papers, 2009.

LUGOSI, Peter. From food, work and organization to the study of hospitality and organization: reconsidering the special issue of human relations. Hospitality and Society, v.1, n. 1, p. 85-89, 2001.

LUGOSI, Peter. Consuming hospitality. In: LASHLEY, C. (Coord.). Routledge Handbook of hospitality studies. Abingdon: Routledge, 2006. p. 220-232.

MARQUES, Gerson. Depoimento [jul. 2019]. Entrevistador: Marcella Sulis Ilhéus. Fazenda Yrerê. 1 arquivo .doc (6 páginas). Entrevista concedida para a pesquisa sobre certificação colaborativa do cacau.

MATOS, Mariana. B. A. Autenticidade em experiências de turismo a partir da Teoria do Pensamento Complexo de Edgar Morin: um estudo sobre vivências em fazendas de cacau no Sul da Bahia. Tese (Doutorado) - Programa de Pós-Graduação em Administração da Universidade Federal de Pernambuco, Pernambuco, 2018.

MAUSS, Marcel. Sociologia e antropologia. São Paulo: Cosac Naif, 2003.

MENDES, Luis. Anuário brasileiro do cacau. Santa Cruz do Sul: Gazeta Santa Cruz, 2016.

MERCADO DO CACAU. Alianças produtivas e IG Cacau Sul da Bahia Viabilizam acesso de agricultores familiares ao Pronaf do Banco do Brasil. 2020. Disponível em: <http:// http://mercadodocacau.com/ artigo/aliancas-produtivas-e-ig-cacau-sul-da-bahia-viabilizam-acesso-de-agricultores-familiares-ao-pronaf $>$. Acesso em: 30 jun. 2020.

MERCADO DO CACAU. Deputado quer transformar Sistema Cacau-Cabruca em patrimônio Cultural e Imaterial. 2018. Disponível em: <https://www.mercadodocacau.com.br/artigo/deputado-quer-transformar-sistema-cacau-cabruca-em-patrimonio-cultural-e-imaterial/rss.xml> Acesso em: 19 dez. 2019. 
MONTANDON, Alain. O livro da Hospitalidade: acolhida do estrangeiro na história e nas culturas. São Paulo: Senac, 2011.

MUSSMAN, Jonathan (Produtor); HARPER, Abigail (Diretor). Rotten: bitter chocolate. Estados Unidos: Netflix, 2019.

PETRINI, Carlo. Slow Food: princípios para uma nova gastronomia. Senac: São Paulo, 2009.

PITT-RIVERS, Julian. The law of hospitality. HAU: Journal of Ethnographic Theory, v. 2, n. 1, p. 501-517, 2012.

POULAIN, Jean-Pierre. Sociologias da alimentação: os comedores e o espaço alimentar. Florianópolis: UFSC, 2013

RAMOS, Maria. Vassoura-de-bruxa. 2006. Disponível em: <http://www. invivo.fiocruz.br/cgi/cgilua.exe/sys/start.htm?infoid=873\&sid=2>. Acesso em: 06 jun. 2020.

RECANATI, Francesca; MARVEGGIO, Davide; DOTELLI, Giovanni. From beans to bar: a life cycle assessment towards sustainable chocolate supply chain. Science of The Total Environment, v. 6130-614, p. 1013-1023, 2018.

REIS, Adriana. Depoimento [jul. 2019]. Entrevistador: Marcella Sulis Ilhéus: Festival Chocolat, 2019. 1 arquivo .doc (5 páginas). Entrevista concedida para a pesquisa sobre certificação colaborativa do cacau.

SALTINI, Rolando; AKKERMAN, Renzo; FROSCH, Stina. Optimizing chocolate production through traceability: a review of the influence of farming practices on cocoa bean quality. Food Control, v. 29, p. 167-187, 2013.

SANTANA, Lilian Dominguez; GOSLING, Marlusa de Sevilha. Imagem de destino turístico: Ilhéus/BA na perspectiva de visitantes e moradores. Caderno Virtual de Turismo, v. 18, n. 2, p. 58-79, 2018.

SETENTA, Wallace; LOBÃO, Dan Érico. Conservação produtiva: cacau por mais 250 anos. Itabuna: Bahia, 2012.

SOUSA, Wandicleia; SILVA, Rubens; VIEIRA, Tiago A. Preservar e resistir: a luta dos pescadores artesanais em defesa do território pesqueiro do Lago do Maicá, em Santarém-Pará. Vivência Revista de Antropologia, v. 1, n. 52, p. 176-190, maio 2019.

TELFER, Elizabeth. A filosofia da "hospitabilidade”. In: LASHLEY, Conrad; MORRISON, Alison (org.). Em busca da hospitalidade: perspectivas para um mundo globalizado. São Paulo: Manole, 2004. p. 53-78.

WALKER, Timothy. Slave labor and chocolate in Brazil: the culture of cacao plantations in Amazonia and Bahia (17th-19th Centuries). Journal Food and Foodways, v. 15, n. 1-2, p. 75-106, 2006.

ZAOUAL, Hassan. A nova economia das iniciativas locais: uma introdução ao pensamento pós-global. Rio de Janeiro: DP\&A; COPPE/ UFRJ, 2006. 